\title{
Sensitivity to Carbohydrate in a Patient with Familial Intermittent Lactic Acidosis and Pyruvate Dehydrogenase Deficiency
}

\author{
STEPHEN D. CEDERBAUM,(45) JOHN P. BLASS, NEIL MINKOFF, W. JANN BROWN, \\ MARY E. COTTON, AND SANDRA H. HARRIS \\ Departments of Psychiatry, Pediatrics, Biological Chemistry, and Pathology, and the Mental Retardation \\ Research Center, UCLA School of Medicine, Los Angeles, California, USA
}

\section{Extract}

A 9-year-old boy with severe mental and growth retardation and diffuse neurologic damage had minimal elevation of blood pyruvate $(0.21 \mathrm{mM})$ and lactate $(2.1 \mathrm{mM})$ on a normal diet but developed life-threatening lactic acidosis $(\mathrm{pH} 7.14$; lactate $21.0 \mathrm{mM})$ on a diet containing $65 \%$ carbohydrates and $15 \%$ fat. Subsequently, blood pyruvate levels rose significantly higher than in 16 control subjects during a glucose tolerance test whereas the glucose levels were normal.

Two sisters died with spontaneous lactic acidosis and an otherwise similar clinical course. Their brains at autopsy were severely deficient in myelin but showed no evidence for active demyelination.

Cultured skin fibroblasts from the patient oxidized $\left[1-{ }^{14} \mathrm{C}\right]$ pyruvate $(0.16 \pm 0.07 \mathrm{cpm} / \mathrm{mg}$ protein $/ \mathrm{min})$ and $\left[2-{ }^{14} \mathrm{C}\right]$ pyruvate $(0.10$ $\pm 0.03)$ to ${ }^{14} \mathrm{CO}_{2}$ at a significantly slower rate than control cells $(0.93 \pm 0.03$ and $0.30 \pm 0.02 ; P<0.001)$, but oxidized $\left[1-{ }^{14} \mathrm{C}\right]$ palmitate, $\left[1,5-{ }^{14} \mathrm{C}\right]$ citrate, $\left[U-{ }^{14} \mathrm{C}\right]$ glutamate, and $\left[1-{ }^{14} \mathrm{C}\right]$ valine normally. The activity of the pyruvate dehydrogenase complex in cell-free extracts $(59 \pm 16 \mathrm{pmol} / \mathrm{min} / \mathrm{mg}$ protein) was significantly less than that for control subjects $\left(389_{ \pm} 35 ; P<0.001\right)$, but the activities of pyruvate decarboxylase and of the 2-oxoglutarate dehydrogenase complex were within the normal range. Pyruvate dehydrogenase levels in extracts of the parents' cells were midway between those of the patients and the control subjects. Mixing experiments, addition of excess cofactor, and studies of activation failed to implicate a soluble inhibitor, abnormal binding of cofactors, or defective activation as causes of the reduced enzyme activity.

The data are consistent with an inherited defect in the second enzyme of the pyruvate dehydrogenase complex, lipoate acetyltransferase (EC. 2.3.1.12). The defect appears to be inherited in an autosomal recessive manner.

\section{Speculation}

Diets low in carbohydrate and enriched in fats may benefit patients with pyruvate dehydrogenase deficiency.

For the past 10-15 years, pyruvic and lactic acids have been reported to accumulate in the blood and urine of occasional patients with developmental retardation and neurologic disease (2, $4,10,21,24,34,35,39)$. More recently, in several of these patients inherited abnormalities affecting specific enzymes of carbohydrate metabolism have been demonstrated. These include deficiencies of the pyruvate dehydrogenase complex $(\mathrm{PDH})(4,9)$, in pyruvate decarboxylase (the first compenent of this complex (PDC; EC. 1.1.4.1)) (3-6, 8, 16, 18, 19, 40) and in pyruvate carboxylase (EC. 6.4.1.1) (11, 13, 23, 37, 38).

We now report studies of a boy with profound mental retardation and intermittent lactic acidosis in whom a brief period on a diet containing $65 \%$ carbohydrates precipitated a severe episode of lactic acidosis and whose two sisters died of the same disorder. His cultured skin fibroblasts proved to be deficient in PDH activity.

\section{CASE REPORTS}

CASE 1

The propositus, JB, was born without complications at term after a normal pregnancy. Birth weight, length, and head circumference were normal. He was hypoactive and hypotonic and was said to have a "peculiar" odor. Psychomotor development virtually ceased by 3 months of age; growth decelerated at 2 years and ended by 4 . Microcephaly was present early but the head continued to grow and is now $2 \mathrm{SD}$ below the mean. During 8.5 years of life, no episodes of acute acidosis, hyperpnea, or lethargy had been noted. He had no seizures. He was not particularly prone to upper respiratory infections despite 4 years in a state hospital. Severe neurologic deficits were noted early and were similar to those described below.

When seen at age 8.5 years, the patient was severely stunted in growth, profoundly retarded, had flexion deformities of the hands and feet, but had no dysplastic features. Weight was $11.4 \mathrm{~kg}$; height, $95 \mathrm{~cm}$; and head circumference, $50 \mathrm{~cm}$. His pulse rate was never found to be below 100. He appeared to hear and see and had no evidence of optic atrophy or retinitis pigmentosa. He could not turn over, sit up, hold his head up, follow, or transfer objects. His posture was dystonic with continual choreoathetoid movements. $\mathrm{He}$ tended to hold his muscles rigidly but was profoundly hypotonic when he relaxed. There were bilateral extensor plantar reflexes. The deep tendon reflexes were normal to slightly increased. There was scissoring, marked primitive reflexes, but there were no apparent deficits of the cerebellar or sensory systems.

There was mild anemia, retarded carpal bone age, and the electroencephalogram was mildly abnormal because of diffuse slowing. Fasting serum cholesterol $(246 \mathrm{mg} / \mathrm{dl})$ and plasma free fatty acids $(0.99 \mathrm{mEq} /$ liter $)$ on a routine hospital diet were minimally elevated. Normal general laboratory studies included electrolytes, blood sugar including one test after a $19-\mathrm{hr}$ fast $(92 \mathrm{mg} /$ dl) and a glucose tolerance test $(1 \mathrm{hr}, 170 ; 2 \mathrm{hr}, 95 ; 3 \mathrm{hr}, 85 ; 4 \mathrm{hr}$, 95) with insulin determinations, serum triglycerides $(51 \mathrm{mg} / \mathrm{dl})$, calcium, phosphorus, magnesium, creatinine, uric acid, serum glutamate-oxaloacetate and glutamate-pyruvate transaminases (SGOT, SGPT), lactate dehydrogenase (LDH), creatine phosphokinase, aldolase, alkaline phosphatase, total serum protein and electrophoresis, quantitative immunoglobulins, VDRL, $\mathrm{T}_{4}$, cerebrospinal fluid (cells, protein, sugar, cultures, and VDRL), electromyogram, nerve conduction velocities, electrocardiogram, $x$-rays of the skull and chest, and karyotype. Red blood cell glycolytic enzymes and ATP were normal.

Fasting blood pyruvate and lactate were normal and rose to 0.21 $\mathrm{mM}$ and $2.1 \mathrm{mM}$, respectively, $2 \mathrm{hr}$ after an ordinary hospital 
meal. Normal values for pyruvate $(0.04-0.14)$ and lactate $(0.55-1.65)$ were determined in our laboratory in children studied under the same conditions. All other normal values used were obtained under comparable conditions in the patient and in control subjects. On two occasions this usual elevation of pyruvate and lactate was not seen. The cerebrospinal fluid level of pyruvate, 0.33 $\mathrm{mM}$, was elevated $(\mathrm{nl} .0 .07-0.14(6,36))$ whereas lactate, $1.8 \mathrm{mM}$, was near the upper end of the normal range. Random specimens of urine usually had mildly elevated levels of alanine of $160-220 \mathrm{mg} / \mathrm{g}$ creatinine vs. a normal of 10-60 mg (31), but on several occasions this was entirely normal. Other urinary amino acids were normal. The plasma alanine level $2 \mathrm{hr}$ after breakfast, $316 \mathrm{mM}$, while the patient was on a normal hospital diet and clinically well, was at the upper end of the normal range (31). Elevations of aspartate (63.4 $\mathrm{mM})$ and serine $(340 \mathrm{mM})$ in that sample are unexplained. In cerebrospinal fluid obtained at the same time, taurine $(56 \mathrm{mM})$ was high and threonine $(16.0 \mathrm{mM})$ was low although other amino acids were normal (14).

On a $65 \%$ fat $/ 15 \%$ carbohydrate diet, the patient's blood bicarbonate fell to $15 \mathrm{mEq} /$ liter and his undiluted serum gave a moderately positive test for ketones with commercial Acetest tablets (Ames, Elkhart, Ind.). Blood pyruvate was then $0.2 \mathrm{mM}$. Neither this diet nor $300 \mathrm{mg} /$ day of thiamine by mouth had any favorable effect on his clinical state or the levels of pyruvate and lactate in blood. Clinical studies of the effects of increased carbohydrate intake will be described below.

\section{CASE 2}

$L A B$, the older sister of the propositus and the first child in this family, was born at term after a normal pregnancy and delivery. Intrauterine activity was described as normal. Birth weight, length, and head circumference were normal and progressed well for 2 years after which marked deceleration of height and weight occurred. She was hypotonic, hypoactive, and had the same "peculiar" odor as the propositus. Neurologic disease and psychomotor retardation were noted by 6 months of age and at 5 years she was described as having spastic quadriplegia with bilateral extensor plantar reflexes, hyperactive deep tendon reflexes, muscle wasting, choreoathetoid movements, and flexion deformities of the hands and feet. She responded to loud noise and light and optic atrophy was suspected.

Later that year, after a fall from bed, hyperventilation and twitching developed which progressed over several hours to grand mal seizures and coma. There was mild acidosis, but the patient improved without specific therapy. The first recognized episode of severe acidosis occurred 1 year later with no obvious predisposing cause. The blood $\mathrm{pH}$ was below 7.0 , glucose was $356 \mathrm{mg} / \mathrm{dl}$ before intravenous therapy, and lactate was markedly elevated (41). "Enormous and unprecedented" amounts of sodium bicarbonate (approximately replacing the total body fluid bicarbonate) were required over 2 days to restore acid-base balance, by which time the blood sugar had returned to normal. Lactate levels returned to normal or occasionally slightly elevated levels (according to the standards of the laboratory used) after this episode. One year later, bilateral bronchopneumonia and seizures with moderate acidosis developed and the patient died within $24 \mathrm{hr}$ primarily as a result of the pneumonia.

Except for extensive bronchopneumonia, the general autopsy was unremarkable. Neuropathologic findings will be discussed below with those of the younger sister.

\section{CASE 3}

$S B$, the fourth and youngest child of this couple, was born after an unremarkable pregnancy and delivery. Because she, too, had the "peculiar" odor, the parents felt immediately that she was destined to be retarded like her siblings. From infancy she had severe growth retardation, microcephaly, premature closure of the fontanels, profound psychomotor retardation, chronic irritability, spastic quadriparesis, hyperreflexia, decerebrate posturing, cho- reoathetosis, scissoring, optic atrophy, and blindness. Except during an episode of iron deficiency anemia, the following laboratory values were normal: electrolytes, calcium, phosphorus, blood sugar, glucose tolerance test, ferric chloride test, blood urea nitrogen, alkaline phosphatase, LDH, creatinine phosphokinase, SGOT, SGPT, aldolase, cholesterol, protein-bound iodine, protein electrophoresis, routine cerebrospinal fluid studies, x-rays of the skull, chest, and wrist for bone age, routine karyotype, complete blood count, and urinalysis.

At 18 months of age, the patient was hospitalized for pneumonia. A mild acidosis at that time required no specific therapy. At 30 months of age, an upper respiratory infection heralded the onset of what was to be the first of numerous episodes of lactic acidosis until her death during such an episode 1 year later. Large quantities of bicarbonate in glucose solution (>100 mEq) were used to treat arterial $\mathrm{pH}$ values as low as 6.79 and lactate levels described in her chart as "very high." On occasion, acidosis would recur 1-4 days after a bout had been successfully controlled. Lactate was normal to slightly elevated between attacks. During several episodes, the test for ketones in the urine was said to have been positive. The general autopsy showed no abnormalities except for patchy bronchopneumonia, fatty metamorphosis of cells adjacent to the central veins of the liver, and deformities of the hands and feet.

\section{FAMILY HISTORY}

Both parents are high school graduates and are clinically normal. There is no consanguinity. They have one normal daughter. Blood lactate $(<10 \mathrm{mM})$ and pyruvate $(<0.08 \mathrm{mM})$ levels in all three were normal $2 \mathrm{hr}$ after a routine lunch. Two siblings of the mother are moderately retarded, the retardation of one said to be because of meningitis and the other occurring after severe trauma in adolescence.

\section{METHODS}

\section{CLINICAL STUDIES}

All experiments were carried out, after obtaining explicit parental consent, on a clinical research ward.

For the glucose tolerance tests, $1.75 \mathrm{~g}$ glucose $/ \mathrm{kg}$ body weight dissolved in water were given orally over a period of $5-10 \mathrm{~min}$. The routine test was performed after an overnight fast and the ketonemic test was performed $6 \mathrm{hr}$ after the last feeding, beginning in the 16th hour of a $65 \%$ fat diet in which $40 \%$ of the calories were given as a commercial medium chain triglyceride preparation. Kenonemia and ketonuria (Acetest tablets, Ames) were present before, during, and after completion of this latter study.

The high carbohydrate diet consisted or ordinary table foods supplemented with small amounts of glucose and contained $65 \%$ of the calories as carbohydrates, $15 \%$ as fat, and $20 \%$ as protein. It was given in three equal feedings a day until the patient became ill (see below). Urine was collected from the time of the first feeding but was not analyzed until after he developed lactic acidosis.

Routine clinical measurements were performed in the clinical Laboratory of the UCLA Center for the Health Sciences by standard procedures. Lactate and pyruvate levels were measured in our laboratory by a minor modification of the enzymatic method described in Sigma Technical Bulletin no. 826-UV. $\beta$-Hydroxybutyrate was measured by the method of McGarry et al. (25). Urinary amino acids were measured by paper chromatography (33) and plasma and spinal fluid amino acids with a Beckman amino acid analyzer (1).

\section{LABORATORY STUDIES}

Materials. Nonradioactive chemicals were the best grades readily available from the usual commercial sources. Radiochemicals were obtained either from New England Nuclear or Amersham-Searle and were used without further purification. 
Fibroblasts, grown and harvested as described previously (3, 9), were studied between 10 and 25 passages for all experiments, although we have found no changes in activities in up to 35 passages. Both control and patient cells had a doubling time of 3 days and were morphologically indistinguishable.

Studies of Intact Cells. Cells were suspended in a volume of phosphate-buffered saline (PBS) (3) to give a final concentration of $150-300 \mathrm{mg}$ protein $/ \mathrm{ml}$. Then $0.1 \mathrm{ml}$ of this suspension was mixed with $0.01 \mathrm{ml} 10^{-3} \mathrm{M}$ substrate containing $10^{5} \mathrm{cpm}{ }^{14} \mathrm{C}$, incubated at $37^{\circ}$ for $1 \mathrm{hr}$ and the radioactive $\mathrm{CO}_{2}$ collected without acidification by allowing the reaction mixture to remain at $4^{\circ}$ for 10 min after the incubation (3). Palmitate bound to albumin was used in lower concentration (3) and prolonged trypsinization was used when citrate was the substrate (9). Boiled cells were used as the "killed control."

Studies of Broken Cells. Fibroblasts from two $75 \mathrm{~cm}^{2}$ T-flasks were washed three times in PBS and suspended in $1 \mathrm{ml}$ saturated ammonium sulfate. They were allowed to stand for $10 \mathrm{~min}$ and then $4 \mathrm{ml}$ Tris buffer $(0.01 \mathrm{M}$ Tris, $\mathrm{pH} 7.4,0.05 \mathrm{M} \mathrm{KCl}, 0.004 \mathrm{M}$ $\mathrm{MgCl}_{2}, 0.03 \mathrm{M}$ nicotinamide, and $0.001 \mathrm{M}$ sodium sulfite) was added. After centrifugation at $10,000 \times g$ for $30 \mathrm{~min}$ and with care to remove as much supernatant as possible, the pellet was resuspended in $1 \mathrm{ml}$ Tris buffer, homogenized, and diluted to $2 \mathrm{ml}$ final volume. In later experiments, the cells were homogenized in a solution containing $40 \%$ glycerol in the same Tris buffer. Comparable results were found with either method of disrupting the cells and, indeed, with sonicated cells. Assays of the total PDH complex (9) and of its first component, PDC (3), were as described previously except that cysteine was replaced with $1 \mathrm{mM}$ dithiothreitol. To test for activation (dephosphorylation) of PDH, extracts were incubated at room temperature 5-15 min in $10 \mathrm{mM}$ $\mathrm{MgCl}_{2}$ and $0.5 \mathrm{mM}-\mathrm{CaCl}_{2}$ before assay. On several occasions, a calculated excess of pig heart $\mathrm{PDH}$ phosphatase was also added $(5,32)$.

To measure the 2-oxoglutarate dehydrogenase complex $(\mathrm{KGDH})$ the same technique was used as for PDH except that 0.2 $\mathrm{mM}$-sodium $\left[1-{ }^{14} \mathrm{C}\right] 2$-oxoglutarate replaced the pyruvate (7).

Electrophoresis of LDH was done in the UCLA Clinical Laboratory with commercial standards. Enzyme assays and kinetic measurements were by a standard spectrophotometric technique (15).
Significance of differences in mean values was determined by Student's $t$-test.

\section{RESULTS}

\section{PATHOLOGY}

The most prominent neuropathologic change in both case 2 and case 3 was lack of myelin without evidence for active demyelination.

In case 2 , myelin was diminished in the spinal cord; markedly in the corticospinal, reticulospinal, and dorsal and ventral spinocerebellar tracts: partially in the gracile tract; and less so in the cuneate tract. Pontine strata fibers were attenuated. Loss of myelin was marked in the hilus of the dentate nucleus, in the radial fibers of the striatum, in subcortical U-fibers, in the centrum ovale, in the corpus callosum (which, however, maintained a normal contour), and in the cerebellar folia (Figs. 1-3). The granule cells of the cerebellum were decreased; the neurons of the cortical strip appeared to be normally distributed. Reactive gliosis to the myelin loss was generally lacking.

In the less extensive material available from case 3 , there was marked demyelination of the cerebrum and enlargement of the lateral ventricles. Beneath the demyelination, some U-fibers were present. Gitter cells and lipid accumulations were not seen. The brain stem appeared to be normal. The spinal cord was not available for examination.

\section{HIGH CARBOHYDRATE DIET}

Significant lactate aciduria occurred in the propositus within 12 $\mathrm{hr}$ of beginning the diet containing $65 \%$ carbohydrate. By $55 \mathrm{hr}$, profound lactic acidosis was clinically obvious (Table 1, Fig. 4). Pyruvate was increased proportionately. The lactate to pyruvate ratio remained normal. Plasma glucose and alanine were significantly elevated as was urinary alanine, especially during hours $60-72$. The highest urinary alanine levels, 440 and $360 \mathrm{mg} / \mathrm{g}$ creatinine, occurred in the third and fourth 12 -hr pooled samples before the onset of clinical acidosis. The remainder of the plasma amino acids were normal, including aspartate and serine previously found to be elevated while the patient was on a normal hospital diet.

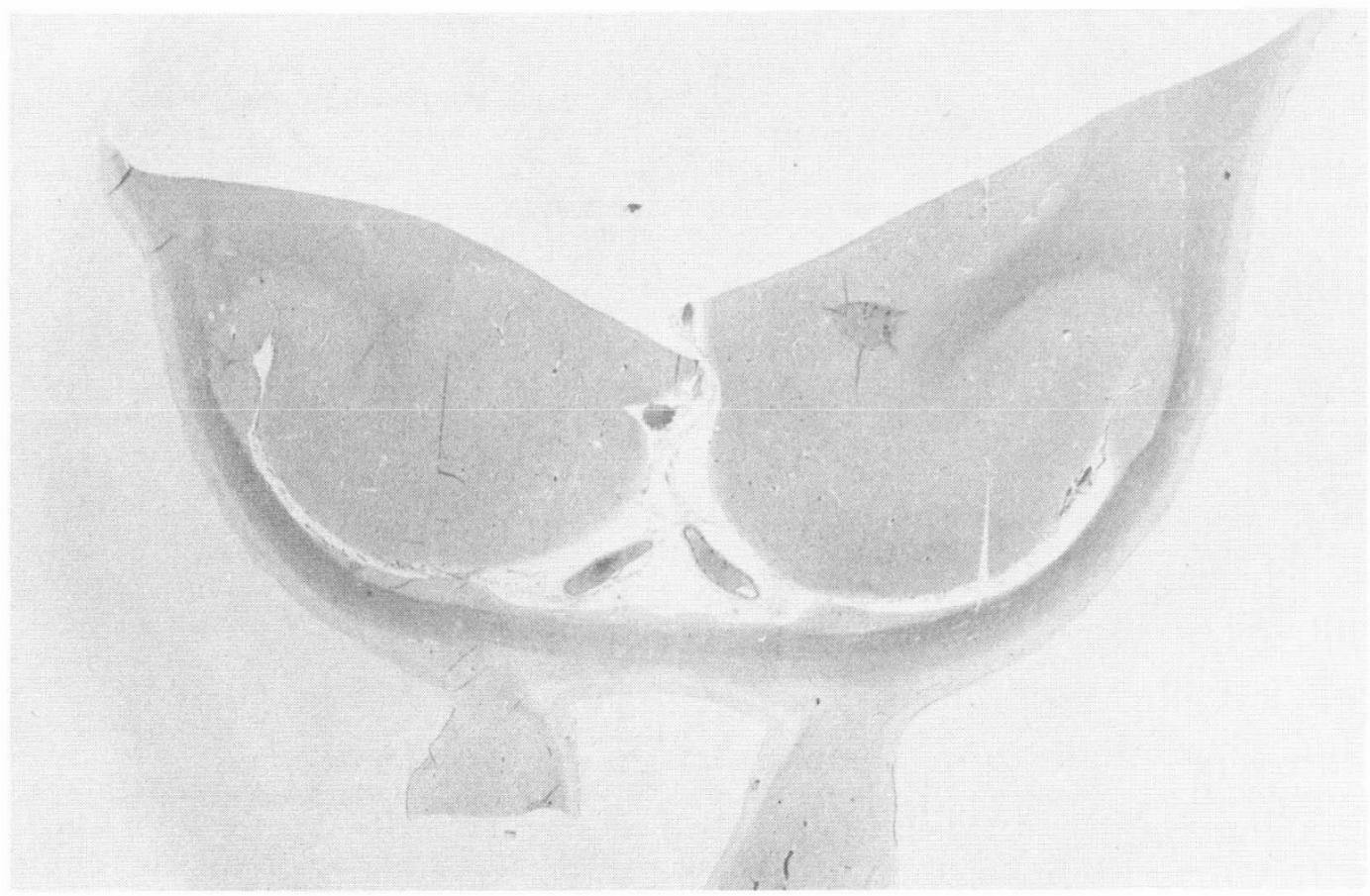

Fig. 1. A thin corpus callosum is seen below both cingulate gyri. It stains very lightly with Luxol blue-periodic acid-Schiff because of its relative lack of myelin. There is a fifth ventricle $\left(\begin{array}{l}\times \\ 7.5\end{array}\right)$. 
During $12 \mathrm{hr}$ of treatment, a total of $650 \mathrm{mEq}$ of bicarbonate, twice his calculated normal body level, was administered using glucose-free parenteral fluids, and more than $30 \mathrm{~g}$ lactate were excreted in his urine. Serum sodium and chloride rose as high as
165 and $116 \mathrm{mEq} /$ liter, respectively. The plasma glucose returned to normal as the acidosis came under control. No other parameter except the appearance of small amounts of $\beta$-hydroxybutyrate in his urine $(1.2,9.0 \mu \mathrm{mol} / \mathrm{mg}$ creatinine $)$ correlated with the sudden

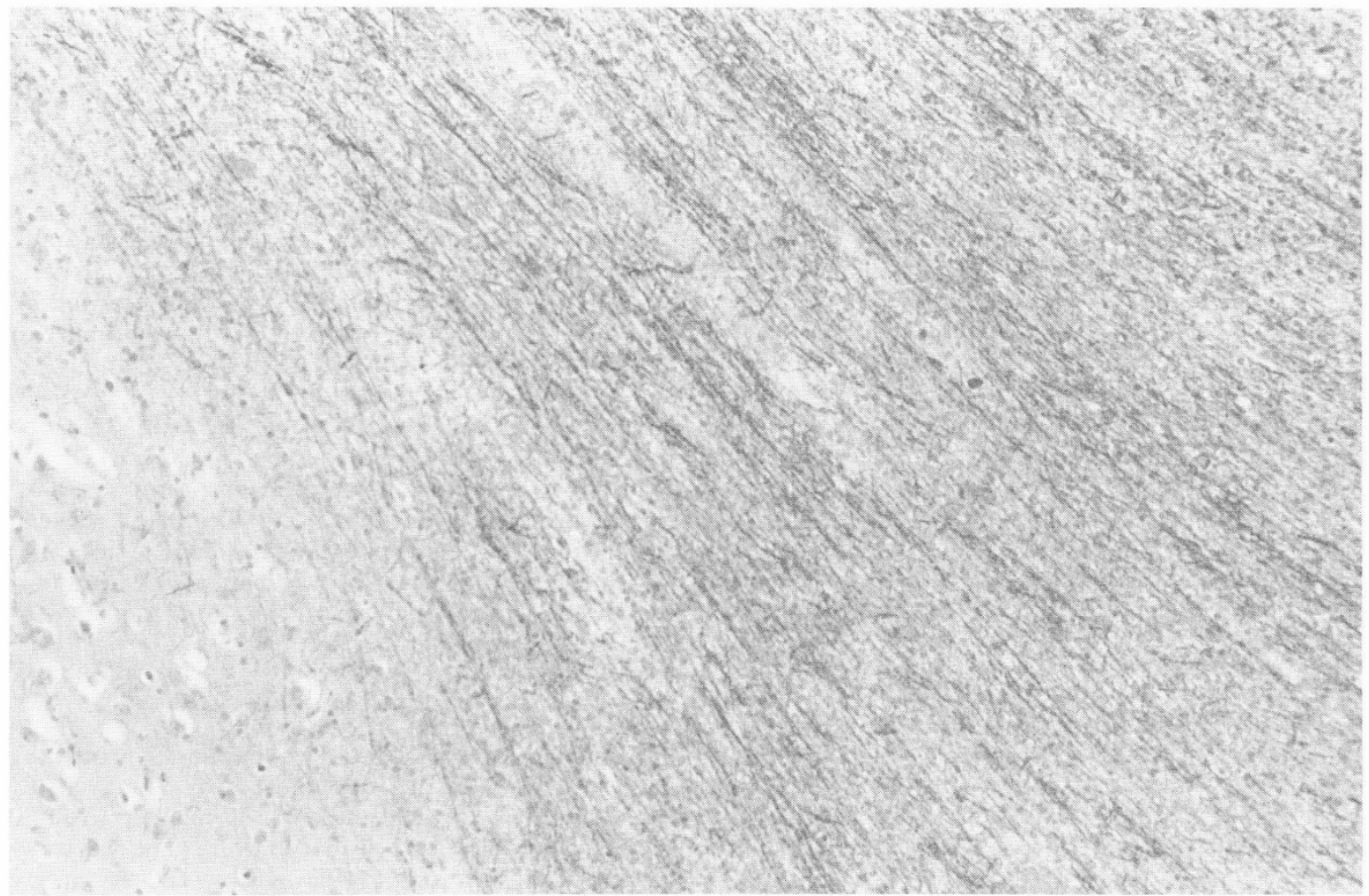

Fig. 2. A small segment of frontal cortex (lower left) is seen with underlying white matter severely deficient in myelin. There is no reactive glial response. Luxol blue-periodic acid-Schiff $(x$

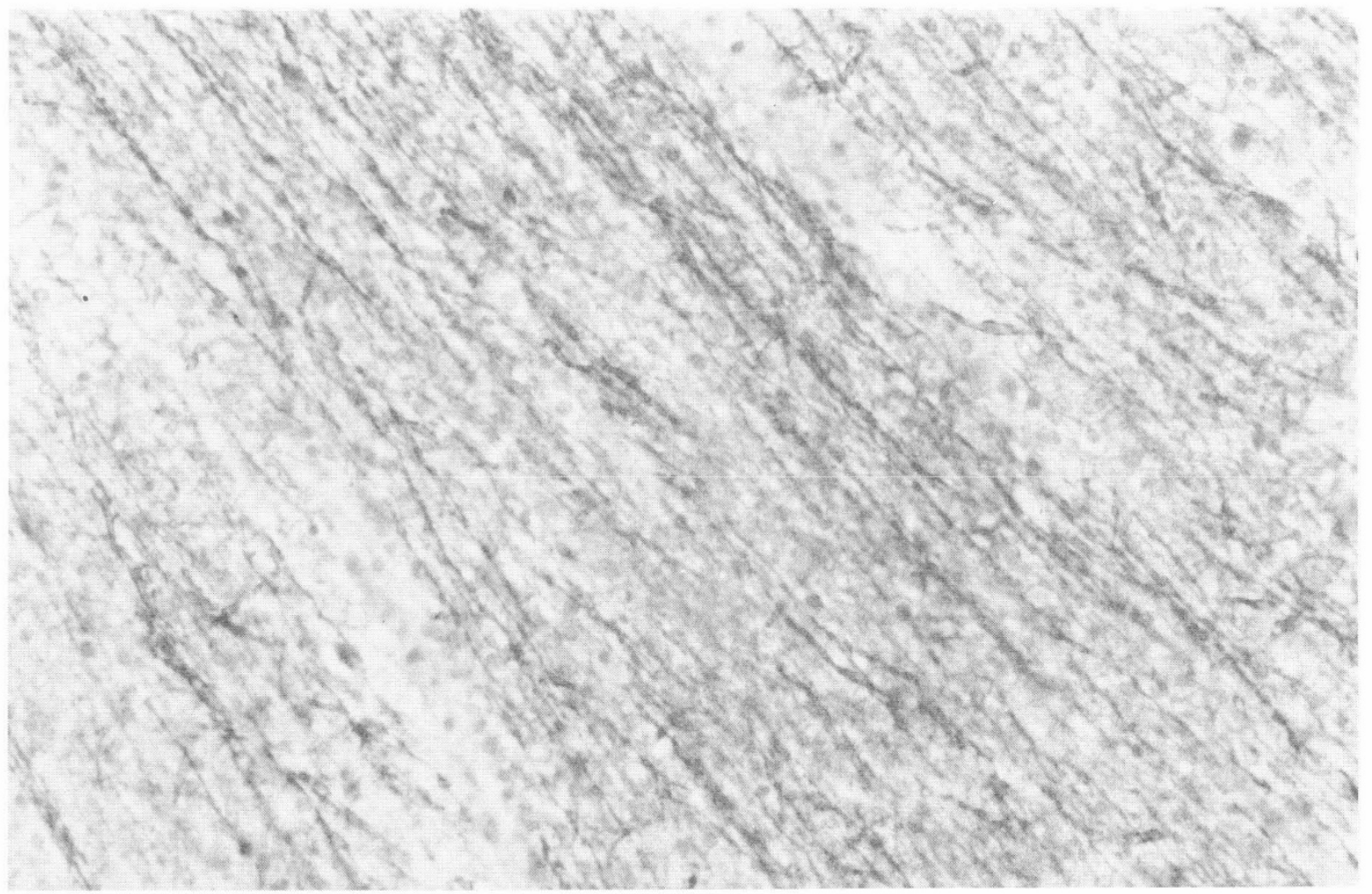

Fig. 3. A higher power view of myelin from the centrum ovale of the frontal lobe showing the paucity of myelin sheaths in a section cut at twice the

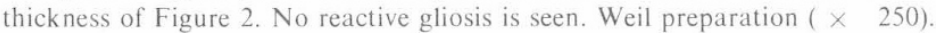


Table 1. Other blood and urine values during carbohydrate-induced lactic acidosis

\begin{tabular}{|c|c|c|c|}
\hline & \multicolumn{2}{|c|}{ Hours } & \multirow[b]{2}{*}{ Normal values $^{1}$} \\
\hline & $48-60$ & $60-72$ & \\
\hline Blood lactate, mM & 8.2 & 21.0 & $0.55-1.65$ \\
\hline Blood pyruvate, $\mathrm{mM}$ & 0.55 & 0.93 & $0.04-0.14$ \\
\hline Lactate to pyruvate ratio & 15.0 & 22.6 & $10-20$ \\
\hline Plasma alanine, $\mathrm{mM}$ & \multicolumn{2}{|c|}{1.91} & $0.22-0.65$ \\
\hline Blood pH & \multicolumn{2}{|c|}{$7.14-7.25$} & $7.35-7.45$ \\
\hline $\begin{array}{l}\text { Plasma bicarbonate, } \\
\mathrm{mEq} / \text { liter }\end{array}$ & \multicolumn{2}{|c|}{$4.0-15.0$} & $22.0-28.0$ \\
\hline Plasma glucose, mg/dl & 250.0 & 350.0 & $65-110$ \\
\hline $\begin{array}{l}\text { Urinary alanine, } \\
\mathrm{mg} / \mathrm{g} \text { creatinine }\end{array}$ & 100.0 & 280.0 & $<60$ \\
\hline Plasma $\beta$-hydroxybutyrate, $\mathrm{mM}$ & \multicolumn{2}{|c|}{$\begin{array}{l}\text { Undetectable } \\
\quad(<0.02)\end{array}$} & $0.014-0.018$ \\
\hline
\end{tabular}

"Sources for normal values are given in the text, except for plasma bicarbonate and plasma glucose which are those determined by the UCLA clinical laboratory and that for plasma $\beta$-hydroxybutyrate, determined by Cahill et al. (12).

control of seemingly intractable and accelerating acidosis. Subsequently, less severe, self-limited episodes of acidosis were recognized, usually in association with minor respiratory infection.

The patient's urine gave a moderate to strong positive test for ketones using commercial Acetest tablets during carbohydrate loading. The color proved to be due to pyruvate which reacts in concentrations as low as $10^{-4} \mathrm{M}$ in water or urine. No acetoacetate or acetone was detected in the patient's urine when the dinitrophenylhydrazine derivatives of the urine were examined by thin layer chromatography (26) and no $\beta$-hydroxybutyrate $(<0.02$ $\mathrm{mM}$ ) was found in the serum or urine when it was analyzed enzymatically. Once the false positive nature of the reaction was appreciated, the vivid purple color caused by ketone bodies was readily distinguished from the dirty grayish purple because of pyruvate. $\alpha$-Ketoglutarate gives a reddish color at higher concentrations. We presume that the positive ketone test in case 3 may also have been because of pyruvate.

\section{GLUCOSE-PYRUVATE TEST}

The levels of pyruvate in the patient's blood during a glucose tolerance test (Fig. 5) were significantly higher than those of 16 children and adults with various other neurologic diseases in whom blood glucose values were also normal. The ketonemia and ketonuria induced acutely by a 16-hr high fat diet rich in medium chain triglycerides did not alter this abnormal pattern. The effect of prolonged high fat intake on this test could not be studied because of the patient's tendency to develop ketoacidosis (see above).

\section{IN VITRO STUDIES}

Whole Fibroblasts. Intact cells from the patient oxidized $\left[1-{ }^{14} \mathrm{C}\right]$ and $\left[2-{ }^{14} \mathrm{C}\right]$ pyruvate at less than one-third the rate of control cells $(P<0.001)$, but the cells converted $\left[1-{ }^{14} \mathrm{C}\right]$ palmitate, $\left[1,5-{ }^{14} \mathrm{C}\right] \mathrm{ci}-$ trate, and $\left[U-{ }^{14} \mathrm{C}\right]$ glutamate to ${ }^{14} \mathrm{CO}_{2}$ at rates comparable with those of controls (Table 2). They also oxidized $\left[1-{ }^{14} \mathrm{C}\right]$ valine at a normal rate. $\left[1-{ }^{14} \mathrm{C}\right]$ Leucine was oxidized significantly faster by the cells of the patient than by control cells in the small number of experiments done. Preincubation of the cells with $1 \mathrm{mM}$ lipoic acid or with $1 \mathrm{mM}$ dinitrophenol did not alter the relative rates of pyruvate oxidation.

\section{DISRUPTED CELLS}

Studies of Patient's Cells. In disrupted cells from the patient, the activity of the PDH complex was less than 20\% that of controls ( $P$
$<0.001$ ) measured in the presence of $\mathrm{NAD}^{+}$and $\mathrm{CoA}$ at $\mathrm{pH} 7.4$. The activities of $\mathrm{PDC}$ and $\mathrm{KGDH}$ were within the normal range (Table 3). A 10- to 100-fold excess of $\mathrm{CoA}$, thiamine pyrophosphate, $\mathrm{NAD}^{+}$, or $1 \mathrm{mM}$ lipoic acid (oxidized or reduced) failed to alter enzyme activity in cells of the patient or controls. Mean values for PDH in extracts of the parents' cells lay midway between those of the patient and controls, whereas those of the healthy sister were normal (Fig. 6).

Mixing experiments failed to implicate a soluble inhibitor as a basis for the low PDH activity in the patient's cells (Table 4). Preincubation of the extracts of both the patient's and control cells with $10 \mathrm{mM} \mathrm{Mg}^{2+}$ and $0.5 \mathrm{mM} \mathrm{Ca}^{2+}$ did not significantly increase PDH activity (Table 5), nor did the addition of partially purified pig heart pyruvate dehydrogenase phosphatase with $\mathrm{Mg}^{2+}$ and $\mathrm{Ca}^{2+}$ increase the activity in extracts of controls cells.

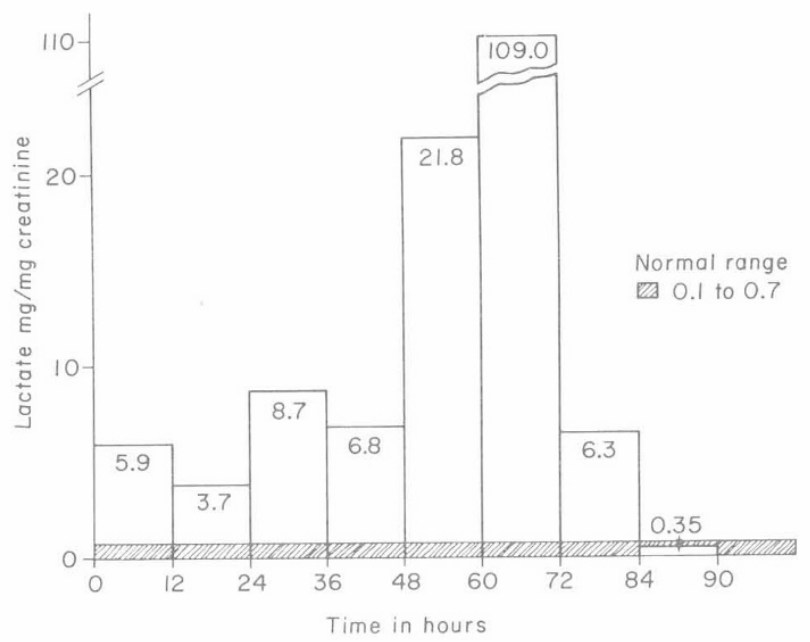

Fig. 4. Lactic acid in the patient's urine after a carbohydrate load. The patient began a diet containing $65 \%$ of the calories as carbohydrate at time 0 . At hour 53 he had his final meal and was then maintained on glucose-free intravenous fluids. The amount of lactic acid is expressed as a ratio to the urinary creatinine. The shaded bar indicates the normal range as determined in 25 subjects from infancy to adolescence, in our laboratory. The patient excreted a total of over $30 \mathrm{~g}$ lactic acid into his urine during the period of hour 36 to hour 72 .

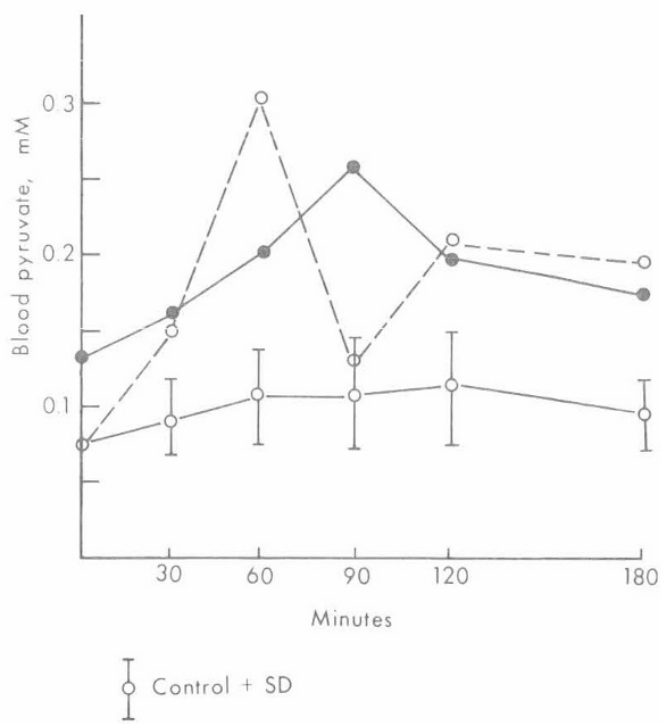

Fig. 5. Glucose-pyruvate test. Blood pyruvate was measured during a standard glucose tolerance test as described in the text. $\$$, values for 16 controls $\pm \mathrm{SD}$ - - fasting study; $\mathrm{O}-\mathrm{O}$, study after a high fat diet. All control subjects had normal glucose tolerance curves. 
Table 2. Oxidation of various substrates by intact fibroblasts

\begin{tabular}{|c|c|c|}
\hline & \multicolumn{2}{|c|}{$\begin{array}{c}\text { Activity }^{1} \\
(\mathrm{cpm} / \mathrm{mg} \mathrm{protein} / \mathrm{min})\end{array}$} \\
\hline & Patient & Control subjects \\
\hline$\left[1-{ }^{14} \mathrm{C}\right]$ Pyruvate & $0.16 \pm 0.07(5)^{2}$ & $0.93 \pm 0.03(30)$ \\
\hline$\left[2-{ }^{14} \mathrm{C}\right]$ Pyruvate & $0.10 \pm 0.03(4)^{2}$ & $0.30 \pm 0.02(18)$ \\
\hline$\left[1-{ }^{14} \mathrm{C}\right]$ Palmitate & $0.69 \pm 0.28(4)$ & $0.73 \pm 0.05(22)$ \\
\hline$\left[1,5-{ }^{14} \mathrm{C}\right]$ Citrate & $0.23 \pm 0.06(2)$ & $0.24 \pm 0.09(9)$ \\
\hline$\left[U-{ }^{14} \mathrm{C}\right]$ Glutamate & $0.19 \pm 0.04(13)$ & $0.27 \pm 0.11(4)$ \\
\hline$\left[1-{ }^{14} \mathrm{C}\right]$ Leucine & $0.072 \pm 0.003(5)^{2}$ & $0.049 \pm 0.005(3)$ \\
\hline$\left[1-{ }^{14} \mathrm{C}\right]$ Valine & $0.091 \pm 0.03$ & $0.051 \pm 0.02(2)$ \\
\hline
\end{tabular}

${ }^{1}$ Cells from the patient and from control subjects were incubated in phosphate-buffered saline with $10^{5} \mathrm{cpm}$ of the appropriate substrate for $60 \mathrm{~min}$ and the ${ }^{14} \mathrm{CO}_{2}$ evolved measured $(3,9)$. Values are mean $\pm \mathrm{SEM}$. The numbers in parentheses refer to the number of lines studied for the control subjects and the number of cultures studied for the patient. At least three cultures were studied for each control subject, except with leucine and valine where two cultures were tested. Each culture was studied in triplicate.

$$
{ }^{2} P<0.001 \text {. }
$$

Table 3. Activities of p!ruvate decarboxylase $(P D C)$ and of the pyruvate and oxoglutarate dehydrogenase complexes in disrupted cells

\begin{tabular}{|c|c|c|}
\hline & \multicolumn{2}{|c|}{$\begin{array}{c}\text { Activity }{ }^{1} \\
\text { (pmol/min } / \mathrm{mg} \\
\text { protein) }\end{array}$} \\
\hline & Patient & Control subjects \\
\hline $\operatorname{PDC}\left(\mathrm{K}_{3} \mathrm{Fe}(\mathrm{CN})_{6}\right.$-linked $)$ & $50 \pm 12$ & $66 \pm 6(10)$ \\
\hline Pyruvate dehydrogenase complex & $59 \pm 16^{2}$ & $389 \pm 35(18)$ \\
\hline 2-Oxoglutarate dehydrogenase complex & $414 \pm 86$ & $309 \pm 61(36)$ \\
\hline
\end{tabular}

${ }^{1}$ Activities were measured as described in the text. Values are means \pm SEM; numbers of control subjects studied are in parentheses. Triplicate determinations were performed on at least three cultures from each individual studied.

${ }^{2} P<0.001$.

The specific activity, electrophoretic isoenzyme pattern, and enzyme kinetics with varying concentrations of pyruvate and NAD were identical for lactate dehydrogenase in the fibroblasts of the patient and of a control subject. In addition, the concentrations of lactate in the cultured fibroblasts and the culture medium were similar for the patient and control subjects at 24 and $48 \mathrm{hr}$ of incubation after change of the culture medium.

\section{DISCUSSION}

This patient and two of his sisters had an inherited disorder that resulted in a severe but intermittent lactic acidosis. Although blood pyruvate and lactate levels were near the upper limits of normal under most circumstances, the defect was apparently severe enough to prevent most postnatal psychomotor development and to stunt growth severely. Life-threatening lactic acidosis occurred quickly in the propositus when he ate a diet containing $65 \%$ carbohydrate and $15 \%$ fat. This is similar to diets we and others have repeatedly given to healthy people without any apparent adverse clinical effects or alterations in blood chemistry (22). The close correlation between the total lactate excreted and the bicarbonate deficit suggests that lactate was the major acidic metabolite produced by the tissues of the patient. Similar sensitivity to carbohydrates (or dependence on fats) has been demon- strated in three other patients with PDC deficiency $(16,17,19)$; another patient with PDH deficiency reportedly did better on a high fat diet, but control studies could not be done (9).

When the carbohydrates in the diet were increased, the fat content was reduced. Fats, either as fatty acids or as ketone bodies, provide a metabolic fuel which bypasses a block at pyruvate oxidation and provides acetyl-CoA for citrate synthesis in the tricarboxylic acid cycle. Lack of adequate substrate for the tricarboxylic acid cycle might be expected to stimulate glycolysis. However, ketonemia induced by $10 \mathrm{hr}$ of lipid feeding did not prevent the usuai rise in pyruvate with glucose loading (Fig. 5). The role and significance of hyperglycemia during the episode of lactic acidosis is not clear.

A deficiency in the oxidation of pyruvate was demonstrated in vitro in this patient's undis upted cultured skin fibroblasts. Oxidation of the fatty acid palmitate, the amino acid glutamate, and the citric acid cycle intermediate citrate were all comparable with control values (Table 2). Enzymatic studies with disrupted fibroblasts (Table 3) confirmed a defect in the PDH complex, which catalyzes the oxidation of pyruvate to acetyl-CoA and $\mathrm{CO}_{2}$. This could not be attributed to an abnormality in the binding of a cofactor, to the presence of a soluble inhibitor (Table 4), or to a failure of activation of the PDH complex by the phosphatase which dephosphorylates inactivated PDC (Table 5). The activity of PDC, measured in the ferricyanide-linked assay at $\mathrm{pH} 6.0$, was within the

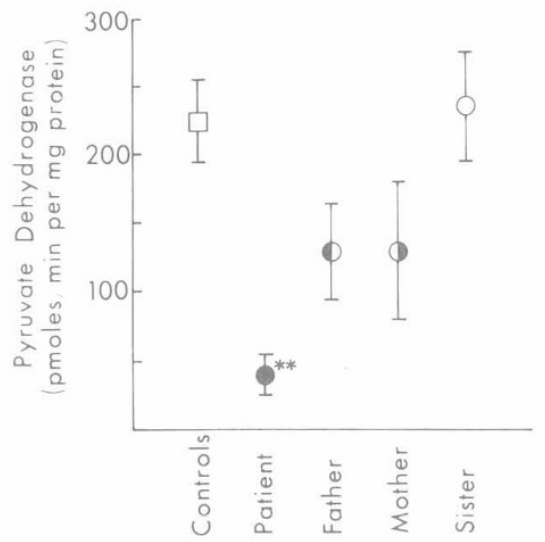

Fig. 6. Pyruvate dehydrogenase activity in disrupted fibroblasts from the patient and his family. The activity of the pyruvate dehydrogenase complex was measured radiochemically as described in the text. The symbols indicate the mean \pm SEM for triplicate determination with 47 cultures from eight control subjects, for 17 cultures from the patient, and for 6-7 cultures for his reiatives. ${ }^{* *}: P<0.001$.

Table 4. Activity of pyruvate dehydrogenase complex in mixtures of disrupted ceils from patient and control subject

\begin{tabular}{|c|c|c|c|c|}
\hline \multicolumn{2}{|c|}{ Protein added } & \multicolumn{2}{|c|}{$\begin{array}{c}\text { Activity }{ }^{1}(\mathrm{pmol} / \mathrm{min} / \\
\text { mg protein) }\end{array}$} & \multirow[b]{2}{*}{$\begin{array}{l}\% \text { found/ } \\
\text { calculated }\end{array}$} \\
\hline $\begin{array}{l}\text { Control } \\
\text { subject }\end{array}$ & Patient & Found & Calculated & \\
\hline 230 & 0 & 237 & & \\
\hline 173 & 67 & 177 & 193 & 91 \\
\hline 115 & 134 & 142 & 151 & 94 \\
\hline 57 & 201 & 96 & 108 & 90 \\
\hline 0 & 268 & 66 & & \\
\hline
\end{tabular}

${ }^{1}$ Activity of the pyruvate dehydrogenase complex (PDH) was measured as described in the text and Reference 9, with mixtures of disrupted fibroblasts from the patient and from a clinically normal individual. Values are the mean of triplicate determinations. One of three similar experiments with different control cell lines is shown. 
Table 5. Effects of divalent cations on pyruvate dehydrogenase activity

Activity, ${ }^{1} \mathrm{pmol} / \mathrm{min} / \mathrm{mg}$ protein

\section{Conditions}

$4 \mathrm{mM} \mathrm{MgCl}_{2}$

$14 \mathrm{mM} \mathrm{MgCl}_{2}$,

$0.5 \mathrm{mM} \mathrm{CaCl}_{2}$

Patient Control subjects

$61 \pm 28(4) \quad 198 \pm 34(7)$

$53 \pm 25(4) \quad 210 \pm 33(7)$
${ }^{1}$ Activities were measured as described in the text. Values are means \pm SEM. Triplicate determinations were done on the number of cultures shown in parentheses. The final concentrations of the compounds added are shown. Results were similar whether the extracts were preincubated with these materials for $20 \mathrm{~min}$ at room temperature, whether the materials were simply added at the beginning of the 30 -min incubations, or whether purified bovine heart pyruvate dehydrogenase complex phosphatase was added.

range for control fibroblasts as was the activity of the KGDH complex. Sakurai et al. (30) has shown that the third enzyme of the PDH complex, lipoamide dehydrogenase (EC. 1.6.4.3), is the same protein in the PDH and KGDH complexes from pig heart.

Thus, by inference, the enzymatic defect appears to lie in the second enzyme of the PDH complex, lipoate acetyltransferase (EC. 2.3.1.12). Direct assay of this enzyme and lipoamide dehydrogenase would be required for this conclusion to be certain, but the assays have proven difficult to adapt to the small amount of material available from cultured fibroblasts. These observations confirm and extend previous studies of cells from another patient with lactic acidosis of childhood $(4,9)$, and are in contrast to most other patients with PDH deficiency in whom the defect appears to be in PDC (3-6, 8, 16, 18, 19).

The values for PDH in the extracts of the parents' cells were midway between those of the patient and control subjects and were in accord with the pedigree data, suggesting that both were heterozygous for a primary inherited deficiency of PDH.

Lactate and pyruvate acidemia has sometimes been described in patients with the subacute necrotizing encephalomyelopathy of Leigh (28). A sample of urine from the propositus did not contain the inhibitor which has been proposed as a test for Leigh's syndrome (29). The necrotic foci, glial reaction, and capillary proliferation characteristic of Leigh's encephalomyelopathy were absent in the brains of the two sisters of the propositus (27). The greatly reduced but normal appearing myelin sheaths and the absence of gliosis both favor a developmental rather than a destructive process in these cases.

The detection of patients with PDH deficiencies remains difficult. The clinical picture is too variable to be diagnostic, although small stature and ataxia have been found frequently thus far (4). Urinary alanine excretion may be normal in the absence of an acute exacerbation and urinary pyruvate and lactate excretion usually does not rise until blood values are more than 2-3 times normal. Postprandial blood pyruvate level, especially after a high carbohydrate meal, appears to be the best clinical test available. In retrospect, the glucose-pyruvate test might have been used to foreshadow the clinical deterioration in this patient and in two others with PDC deficiency who were fed a high carbohydrate diet. Confirmation of the diagnosis may be accomplished using cultured skin fibroblasts; rapid diagnosis would require enzyme assays in biopsied liver at the present time. The discovery of two families with PDH deficiency at UCLA in a short period of time and reports of an increasing number of isolated patients suggest that this condition may not be rare.

Although it is easy to assume that even a partial deficiency of so critical an enzyme as that responsible for producing acetyl-CoA from glucose and pyruvate should lead to a severe developmental disability, the precise relationship between the defect and the pathogenesis and the carbohydrate sensitivity remains to be elucidated. In animals, moderate deficiencies in the oxidation of carbohydrates do not lead to reductions in the levels of ATP or in the energy charge potential in the brain but do impair biosynthetic activities including the synthesis of acetylcholine $(4,20)$.

\section{SUMMARY}

A 9-year-old, severely retarded, neurologically damaged boy with minimal elevations of blood pyruvate and lactate levels developed severe lactic acidosis on a high carbohydrate diet. Two affected sisters had spontaneous episodes of lactic acidosis and were found at autopsy to be severely myelin deficient in the brain. Study of whole and disrupted skin fibroblasts revealed a deficiency in pyruvate dehydrogenase complex activity which was inherited in an autosomal recessive manner.

\section{REFERENCES AND NOTES}

1. Benson, Jr., J. V., Gordon, M. J., and Patterson, J. A.: Accelerated chromatographic analyses of amino acids in physiological fluids containing glutamine and asparagine. Anal. Biochem., 18: 228 (1967).

2. Binkiewicz, A., Jungas, R. L., Hockman, H., and Senior, B.: Familial idopathic lactic acidoss-Petite mutant disease in man? [Abstract]. Pediat. Res. 6: 135 (1972).

3. Blass, J. P., Avigan, J., and Uhlendorf, B. W.: A defect in pyruvate decarboxylase in a child with an intermittent movement disorder. J. Clin. Invest. 49: 423 (1970).

4. Blass, J. P., Cederbaum, S. D., and Gibson, G. E.: Clinical and metabolic abnormalities accompanying deficiencies in pyruvate oxidation. In: F. A Hommes and C. J. van den Berg: Normal and Pathological Development of Energy Metabolism, p. 193 (Academic Press, New York, 1975).

5. Blass, J. P., Gibson, G. E., and Kark, R. A. P.: Pyruvate decarboxylase deficiency. In: P. M. Dreyfus and C. J. Gubler: Thiamine Deficiency (Wiley, New York, 1976).

6. Blass, J. P., Kark, R. A. P., and Engel, W. K.: Clinical studies of a patient with pyruvate decarboxylase deficiency. Arch. Neurol., 25: 449 (1971).

7. Blass, J. P., Kark, R. A. P., and Menon, N. K.: Low activities of the pyruvate and 2-oxoglutarate dehydrogenase complexes in fibroblasts from five patients with Friedreich's ataxia. N. Engl. J. Med. (In press.)

8. Blass, J. P., Lonsdale, D., Uhlendorf, B. W., and Hom, E.: Intermittent ataxia with pyruvate decarboxylase deficiency. Lancet, $i$ : 1302 (1971).

9. Blass, J. P., Schulman, J. D., Young, D. S., and Hom, E.: An inherited defect affecting the tricarboxylic acid cycle in a patient with congenital lactic acidosis. J. Clin. Invest, 51: 1845 (1972).

10. Brown, R. E., Madge, G. E., and Mamunes, P.: Chronic lactic acidosis in infancy. Arch. Pathol. 94: 192 (1972).

11. Brunett, M. G., Delvin, E., Hazel, B., and Scriver, C. R.: Thiamine responsive lactic acidosis in a patient with deficient low $\mathrm{Km}$ pyruvate carboxylase activity in liver. Pediatrics, 50: 702 (1972).

12. Cahill, G. F., Jr., Herrera, M. G., Morgan, A. P.. Soeldner, J. S., Steinke, J., Levy, P. L., Reichard, G. A., Jr., and Kipnis, D. M.: Hormone-fuel interrelationships during fasting. J Clin. Invest., 45: 175! (1966).

13. DeGroot, C. J., and Hommes, F. A.: Further speculation on the pathogenesis of Leigh's encephalomyelopathy, J. Pediat. 82: 541 (1972).

14. Dickinson, J. C., and Hamilton, P. B.: The free amino acids of human spinal fluid determined by ion exchange chromatography. J. Neurochem., 13:1179 (1966).

15. Everse, J., and Kaplan, N. O.: Lactate dehydrogenases: Structure and function. Advan. Enzymol., 37: 61 (1973).

16. Falk, R. E., Cederbaum, S. D., Blass, J. P., Pruss, F. J., and Carrel, R. E. Clinical and biochemical response to a ketogenic diet in two brothers with pyruvate dehydrogenase deficiency [Abstract]. Pediat. Res., 9: 350 (1975).

17. Falk, R. E., Cederbaum, S. D., and Carrel, R. E.: Pyruvate and lactate acidemia in two retarded hypotonic brothers [Abstract]. Amer J. Hum. Genet., 26: 29a (1974).

18. Farmer, T. W., Veath, L., Miller, A. L., O'Brien, J. S., and Rosenberg, R. M.: Pyruvate decarboxylase deficiency in a patient with subacute necrotizing encephalomyelopathy [Abstract]. Neurology, 23: 429 (1973).

19. Farrell, D. F., Clark, A. F., Scott, C. R., and Wennberg, R. P.: Absent pyruvate decarboxylase in man: A cause of congenital lactic acidosis. Science, 187: 1082 (1975).

20. Gibson, G. E., Jope, R., and Blass, J. P.: Reduced acetylcholine synthesis accompanying impaired pyruvate oxidation in rat brain minces. Biochem. J. $148 ; 17$ (1975).

21. Greene, H. L., Shubert, W. K., and Hug, G.: Chronic lactic acidosis of infancy. J Pediat., 76: 853 (1970)

22. Herman, R. H., Zakim, D., and Stifel, F. B.: Effect of diet on lipid metabolism in experimental animals and man. Fed. Proc. 29: 1302 (1970).

23. Hommes, F. A., Polman, H. A., and Reerink, J. D.: Leigh's encephalomyelopathy an inborn error of gluconeogenesis. Arch. Dis. Childhood, 43: 423 (1968).

24. Lie, S. O., Loken, A. C., Stromme, J. H., and Aagenaes, H.: Fatal congenital lactic acidosis in two siblings. I. Clinical and pathological findings. Acta Pediat. Scand., 60: 129 (1971) 
25. MacGarry, J. D., Guest, M. J., and Foster, D. W.: Ketone body metabolism in the ketosis of starvation and alloxan diabetes. J Biol. Chem., 245: 4382 (1970).

26. Menkes, J. H.: The pattern of urinary alpha keto acids in various neurological diseases. Amer. J. Dis. Child. 99: 500 (1960).

27. Montpetit, V. J. A., Andermann, F., Carpenter, S., Fawcett, J. S., ZborowskaSluis, D., and Giberson, H. R.: Subacute necrotizing encephalomyelopathy. Brain, 94: 1 (1971).

28. Pincus, J. H.: Subacute necrotizing encephalomyelopathy (Leigh's disease): A consideration of clinical features and etiology. Develop. Med. Child Neurol. 14: 98 (1972).

29. Pincus, J. H., Cooper, J. R., Katalin, P., and Turner, V.: Specificity of the urine inhibitor test for Leigh's disease. Neurology, 24: 885 (1974).

30. Sakurai, Y., Fukuyoshi, Y., Hamada, M., Hayakaua, T., and Koike, M. Mammalian alpha-keto acid dehydrogenase complexes. VI. Nature of the multiple forms of pig heart lipoamide dehydrogenase. J. Biol. Chem., 245: 4453 (1970).

31. Shaw, K. N. F.: Unpublished observations.

32. Siess, E. A., and Wieland, O. H.: Purification and characterization of pyruvate dehydrogenase phosphatase from pig heart muscle. Eur. J. Biochem. 26: 96 (1972).

33. Shaw, K. N. F., Gutenstein, M., Jacobs, E. E., and Blaskovics, J. C.: Biochemical screening and monitoring of patients with phenylketonuria and variant forms of hyperphenylalaninemia. In: H. Bickel, F. P. Hudson, and L. I. Woolf: Phenylketonuria, p. 163 (George Thieme, Stuttgart, 1971).

34. Skrede, S., Stromme, J. H., Stokke, O., Lei, S. E. Eldjarn, L.: Fatal congenital lactic acidosis in two siblings. II. Biochemical studies in vivo and in vitro. Acta Pediat. Scand., 60: 138 (1971).

35. Stimmler, L., Jensen, N., and Toseland, P.: Alaninuria associated with microcephaly, dwarfism, enamel hypoplasia, and diabetes mellitus in two sisters. Arch. Dis. Childhood, 45: 682 (1970).

36. Svenningsen, N. W., and Siesjö, B. K.: Cerebrospinal fluid lactate/pyruvate ratio in normal and asphyxiated neonates. Acta. Paediat. Scand., 61: 117 (1972).

37. Tada, K. Sugita, K., Fujitoni, K., Uesaki, T., Takado, G., and Omura, K. Hyperalaninemia with pyruvicemia in a patient suggestive of Leigh's emcephalomyelopathy. Tohoku J. Exp. Med., 109: 13 (1973).

38. Tada, K., Yoshida, T., Konno, T., Wada, Y., Yokoyama, Y., and Arakawa, T. Hyperalaninemia with pyruvicemia. Tohoku J. Exp. Med., 97: 99 (1969).

39. Many of the original articles describing patients with elevated levels of pyruvate and lactate in the blood are enumerated in Reference 4; the others known to us are listed separately.

40. This enzyme is more correctly called pyruvate dehydrogenase, but because of the use of the name pyruvate decarboxylase (from the analogous yeast enzyme, EC. $4.1,1,1)$ in describing the enzyme defect in the first patient with this disorder, it has come into general use. It is in some ways preferable as it bypasses the ambiguity in thinking of the pyruvate dehydrogenase component of the pyruvate dehydrogenase complex.

41. Lactate values in patient 2 and patient 3 were probably neither very accurate nor directly comparable with those done in our laboratory, so numerical values have not been given.

42. We wish to thank Dr. Mario Valente and the Pediatric House Staff for help in caring for the patient; Dr. R. A. Pieter Kark for the neurologic examinations; and Dr. George Popjak for valuable support.

43. This research was supported in part by the State of California Department of Mental Hygiene and by United States Public Health Service Grants HD-04612, HD-00315, HD-05061, HD-06576, HD-05615, and RR-865.

44. The work was presented in part at meetings of the American Society of Human Genetics (Amer. J. Hum. Genet., 24: 23a (1972)) and the American Federation for Clinical Research (Clin. Res., 21: 530 (1973).

45. Requests for reprints should be addressed to: S. Cederbaum, M. D., Neuropsychiatric Institute, 760 Westwood Plaza, Los Angeles, Calif. 90024 (USA).

46. Accepted for publication February 17, 1976.

\title{
Experience with a Direct Reading Dedicated Fluorometer for Determination of Erythrocyte Protoporphyrin
}

\author{
R. KLEIN, (4) P. USHER, AND P. MADIGAN \\ Childhood Lead Poisoning Prevention Program, The Commonwealth of Massachusetts Department of Health, \\ Jamaica Plain, Massachusetts, USA
}

\section{Extract}

Data are presented for erythrocyte protoporphyrin (EP) concentrations determined by the direct reading technique of Lamola $e t$ al. (1). Mean concentration of EP in children whose blood lead concentration was less than $30 \mu \mathrm{g} / \mathrm{dl}$ was $34.7 \mu \mathrm{g} / \mathrm{dl}$ whole blood \pm 13.4 (SD). Mean EP concentration in children with blood lead concentrations of $40-59 \mu \mathrm{g} / \mathrm{dl}$ was $80.8 \mu \mathrm{g} / \mathrm{dl}$. It was $158 \mu \mathrm{g} / \mathrm{dl}$ for children with blood lead concentrations greater than $59 \mu \mathrm{g} / \mathrm{dl}$. All children in this last group had concordant values for $\mathrm{Pb}$ and $\mathrm{EP}$ on the first or second test.

\section{Speculation}

Screening for lead poisoning using capillary blood determination of erythrocyte protoporphyrin as determined by the direct reading dedicated fluorometer is adequate for ascertaining all children in possible need of immediate treatment. The authors believe, however, that screening should be done using both EP and blood lead determinations. The goal of lead poisoning control programs is to eliminate childhood lead poisoning by preventing exposure to lead hazards. Even after elimination of values from children with transient elevation of blood lead concentrations and those with falsely elevated concentrations because of contamination or laboratory error there is a significant number of children with blood lead concentrations of 40-59 $\mu \mathrm{g} / \mathrm{dl}$ who do not have elevated EP concentrations. Opportunities for protecting these children from further lead paint hazards will be lost.

Measurement of erythrocyte protoporphyrin concentration in blood in children at risk for lead poisoning is of recognized value for lead poisoning prevention programs. The development of the direct reading instrument reported by Lamola et al. (1) makes the determination simple and quick. This report relates our experience with a prototype instrument made available to us for use in June-August 1975 (3). 